\title{
Using Metaheuristics-Based Methods to Provide Sustainable Market Solutions, Suitable to Consumer Needs
}

Ricardo Simões Santos ${ }^{*}, 1$, António João Pina da Costa Feliciano Abreu², Joaquim José Rodrigues Monteiro ${ }^{3}$

${ }^{1}$ GOVCOPP Universidade de Aveiro, ISEL, Polytechnic Institute of Lisbon, 1959-007, Portugal

${ }^{2}$ CTS-UNINOVA Universidade Nova de Lisboa, ISEL, Polytechnic Institute of Lisbon, 1959-007, Portugal

${ }^{3}$ INESC-ID Lisboa, ISEL, Polytechnic Institute of Lisbon, Portugal, 1959-007, Portugal

\author{
A R T I C L E I N F O \\ Article history: \\ Received: 01 January, 2020 \\ Accepted: 19 March, 2020 \\ Online: 04 April, 2020
}

Keywords:

Sustainability

Energy efficiency

Household Appliances

Multi-criteria

Multi-objective Optimization

Evolutionary Algorithms

Simplex

\begin{abstract}
A B S T R A C T
Nowadays the buildings sector is one of the key sectors to achieve sustainability, with the correspondent consumers, in particular, the household consumers, having the need to perform sustainable choices every day, regarding the appliances to be acquired from the market. This is not only due to government's growing concerns about sustainability but also with the consumers on having sustainable solutions, given the different economic, social (including their comfort) and environmental needs. However, the existence of several electrical appliances on market, with all their different issues, brands and models, together with the several tradeoffs referred before, difficult the consumer's choices, on having sustainable solutions in the market. Therefore, this work, presents an approach, by using Multi-Attribute Value Theory (MAVT), integrated with metaheuristics, which uses Evolutionary Algorithms (EA) to provide suitable and sustainable market solutions to a consumer, according to its own needs. Based on the achieved solutions and considering the relative importance, given to each consumer, and regarding each dimension of sustainability, it's possible to achieve several savings, namely electrical and water consumption, $\mathrm{CO}_{2}$ emissions, among others. A case study shall be shown, to demonstrate the applicability of the proposed approach.
\end{abstract}

\section{Introduction}

This paper is an extension of work [1] originally presented in 2019 International Young Engineers Forum (YEF-ECE), held in Nova University, Costa da Caparica, Lisbon, Portugal.

Sustainable measures are relevant to reach environmental and economic sustainability, particularly regarding the reduction of energy production dependency from fossil fuels, where buildings account for about 30-43\% of the final energy consumed [2-3].

Based on [4], and from the percentage referred above, the household's sector represents approximately $18 \%$ of the final electric energy consumed in the world, which represents an important sector to be improved in terms of energy efficiency, and through the adoption of sustainable appliances.

According to [5-7], there were some improvements regarding energy efficiency, and related to electrical appliances, by

\footnotetext{
${ }^{*}$ Ricardo Santos, Email: ricardosimoessantos84@gmail.com
}

establishing reglementary labeling measures, to provide relevant information to the consumer.

Some of these issues include energy consumption, machine's noise, refrigerator capacity, water consumption, among others [7].

According to [7], such measures, have been arisen, not only in the European countries but as well as in other world regions, such as Africa, America and Asia.

Although the importance of such measures to reach sustainability, there are too much options available in the market, which makes it difficult to know what's the best solution to choose, in order to attend the consumer's needs [6-7].

The difficulty raises, when each appliance has its own set of features, which can be different according to the appliance's brand and model to acquire [4-5].

Considering the diversity of options from the market, and related to each energy service (e.g. lighting, air conditioners, refrigerators, etc.), the number of possible combinations could exponentially rise. 


\section{R.S. Santos et al. / Advances in Science, Technology and Engineering Systems Journal Vol. 5, No. 2, 399-410 (2020)}

The use of optimization algorithms, to assist the consumer on its decisions, allows the achievement of efficient and even sustainable solutions, regarding the household appliances to acquire.

However, and due the high combinatorial nature of the problem referred before, the use of traditional optimization techniques, could present some disadvantages, regarding the efficiency on reaching a feasible solution, as well as with the number of potential and feasible solutions available to the consumer [8]. This could happen, since that some optimization techniques, based on gradient methods, could be stuck into to a local maxima or minima, limiting therefore, the exploitation of the entire feasible region [89].

An alternative way to surpass such disadvantages, could pass by using Evolutionary Algorithms (EA), given the widely use, reflected on the number of works from the literature, on solving optimization problems in less time than other traditional optimization methods (e.g. [8-12]).

Other approaches have been used by the authors, in order to develop an integrated approach that allows to achieve sustainable solutions.

In [1][13-14] the authors have started to use a single objective approach to achieve efficient solutions from the market of household appliances.

The successful contribution to the main goal of their research, have led them to adapt the first approach into a Multiobjective one, given the several dimensions of sustainability (referred before) to attend, and considering each household appliance, related to each energy service to be acquired, namely; Economic, Social and Environment.

In order to consider other kind of consumer's issues, such as its social preferences (e.g. reliability, design, performance, among others) we've applied multiple-attribute value theory (MAVT). This theory allows to model the consumer's choices, as well as other preferences regarding the environment (e.g. CO2 savings, water savings, noise, among others) and the economic dimension (e.g. initial investment, noise, water consumption, among others) [15].

All the dimensions referred above have some constraints, suitable to each case (e.g. number of building occupants, area of the room to be climatized, the type of division, among others), such as the ones related with human comfort (e.g. minimum illuminance to achieve visual comfort, noise, minimum air conditioner to achieve heating comfort), with economy (e.g. budget, water consumption), and environmental (e.g. water savings, $\mathrm{CO}_{2}$ savings, among others). To maximize each dimension, modelled according to MAVT, it was used optimization techniques to get sustainable solutions from the market to the consumer, by acting on three dimensions (or objective functions) referred before.

According to [16], Evolutionary Algorithms (EA), have been applied with success, to solve many optimization problems within less time, when compared with other methods. However, such methods, uses too many control parameters, which makes them, quite sensitive to the input values, therefore, the need to adjust them [16-17], by preforming some robustness and sensitive tests.

The aim of this research, is to propose an approach, where MAVT is integrated with Non-Dominated Sorting Genetic Algorithm II (NSGAII) [18], based on genetic algorithms (GAs), in order to provide the consumer with sustainable solutions from the market, that not only attends it needs, but as well the tree dimensions referred before; Economic, Social and Environmental. To pursue this goal, we've tested, validated and presented in [1], a first approach, which has consisted in one objective function regarding the economic dimension, where it was tried different problem formulations, to study their influence in terms of results.

Based on the works presented on [1] we've selected the objective function with the best results and tested the entire model's robustness, regarding the influence of GAs parameters. Some results are presented with this preliminary approach.

The $2^{\text {nd }}$ approach presented here, will integrate the developments achieved with the $1^{\text {st }}$ one, into a Multiobjective model by using NSGAII optimization method, where not only economic dimension will be included, but also the environmental one as well. For this purpose, new attributes will be added to the model, regarding the environmental dimension, whose diversity and the correspondent units involved, will be integrated into a unique model by recurring to MAVT.

Finally, it will be obtained a combined solution that attends the economic and environmental dimensions, in order to pursue the main goal referred before. A case study will be presented here, to illustrate the applicability of the method, by presenting an example of a set of a feasible and sustainable solutions, suitable to the consumer needs.

\section{Literature review}

Several methods such as scenario's analysis (e.g. [19]), are frequently used to simulate a constrained set of solutions.

However, some methods are essentially economical, by allowing the consumers to obtain highest values of energy savings, given the same value of investment (e.g. [17]). Other methods, existed on literature, allows to deal with different issues (e.g. savings with Greenhouse Gas (GHG) emissions, benefit-cost analysis, initial investment costs, among others). Such methods are mainly related to retrofitting measures (e.g. [20]), where some of them are even combined with technologies too (e.g. [21]).

However, there is some limits with these approaches, since they don't consider other relevant factors, such as the environment, the labelling system and legal and social issues as well, to find suitable solutions, to fulfill the requirements of the occupants of the building. These methods also don't consider the attributes, regarding each electrical appliance, which varies according to the number of building's occupants.

Recently, some works are based on multi-criteria decisionmaking (MCDM) methods, in order to help a consumer to solve his problems regarding the measures of retrofitting with their own building's, by accounting not only energy efficiency factors, but also assuring the comfort of the building's occupants (e.g. [15]).

Regarding other works from the literature, there is other MCDM models, based on MAVT approaches, allowing therefore, the integration of optimization with multicriteria methods, which allows the achievement of feasible solutions, selected based on a set of attributes, organized according to a set of criteria (e.g. [15]).

However, these methods don't account the different attributes, related to each electrical appliance existed on market and adjusted to the individual needs of the occupants.

The use of Metaheuristics to achieve from the energy problems' solving, a set of feasible solutions (e.g.[8], by using particle swarm optimization, e.g. [11], by using genetic algorithms, among others existed on literature), have been increased in the last years. However, none of these approaches, have been considered 
into a combined method, that allows the consumer, to pick from the market, a set of sustainable appliances, based on its preferences.

\section{Objectives}

In order to fulfill the gap referred on literature review, the main objective of this research work is to present an approach to assist an household consumer, who wants to buy sustainable appliances, existed on market, for its home, that not only allows to fulfill its needs, but also allows to accomplish a set of requirements regarding sustainability, based on the three dimensions of sustainability referred before, namely, the Consumer's economic well-being, social well-being and Consumer's environment wellbeing.

Additionally, it will be presented two approach, which allows to obtain several and alternative solutions from the market, facing therefore, some contingencies that eventually may occur, namely the situations of "out of stock" for instance, given an electrical appliance initially recommended by this method.

The approach developed here, also considers economic, social and environment constraints, regarding each energy service considered in this work.

\section{Research Method}

\subsection{Problem description and case study}

The problem presented in this work has considered a consumer, who is intended to acquire a set of household appliances, available on market.

The pre-criteria, considered by the algorithm to pre-select a set of appliances existed on market (Table 1), were instantiated according to the number of occupants, existed in the building. In this case study, it was considered a family (which includes the decision-agent) of 4 occupants.

Table 1: Criteria used

\begin{tabular}{|c|c|c|}
\hline Criteria used & Appliance & Quantity \\
\hline $\begin{array}{l}\text { - Air conditioners (types) } \\
\text { considered: } \\
\text { - Zone to be heated/ cooled by } \\
\text { the air conditioner } \\
\text { - Capacity (minimum) }\end{array}$ & $\underset{\text { Air }}{\text { Conditioner }}$ & $\begin{array}{l}\text { - Mono split } \\
\text { Multisplit, } \\
\text { Portable } \\
\text { - Living room } \\
\text { - } 9923,7 \text { BTU } \\
\end{array}$ \\
\hline $\begin{array}{l}\text { - Capacity, based on the } \\
\text { number of household's } \\
\text { occupants }\end{array}$ & $\begin{array}{l}\text { Washing } \\
\text { Machine }\end{array}$ & - $5 \mathrm{~kg}$ \\
\hline - Load capacity. & Dishwasher & - 10 Cutleries \\
\hline $\begin{array}{l}\text { - Useful volume, available for } \\
\text { cooking based on the number } \\
\text { of occupants }\end{array}$ & Oven & - $44,2 \mathrm{~cm} \times 61,8 \mathrm{~cm}$ \\
\hline $\begin{array}{l}\text { - Type of dryer machines } \\
\text { - Load capacity }\end{array}$ & $\begin{array}{c}\text { Dryer } \\
\text { machine }\end{array}$ & $\begin{array}{l}\text { - By condensation; } \\
\text { - } 6 \mathrm{~kg}\end{array}$ \\
\hline - Technology & Lighting & $\begin{array}{l}\text { - Halogen } \\
\text { - CFL } \\
\text { - Fluorescent }\end{array}$ \\
\hline $\begin{array}{l}\text { - Capacity of the fridge } \\
\text { - Type of fridge, based on the } \\
\text { number of occupants }\end{array}$ & Refrigerator & $\begin{array}{l}\text { - } 120 \text { liters } \\
\text { - Refrigerator } \\
\text { Combined type. }\end{array}$ \\
\hline
\end{tabular}

However, the values regarding each attribute, can be modified, based on the number of occupants, existed in the building.
Thus, the appliances, was pre-selected from the market, by using the criteria presented on Table 1, in order to reduce the decision space, considering therefore, only the suitable solutions to the consumer needs. This was done, in order to increase EA's efficiency, regarding both approaches, by achieving optimal solutions with less time.

\section{2. $1^{\text {st }}$ Approach - Single objective model}

The $1^{\text {st }}$ approach, proposed in this work, can be seen on Figure 1, where each consumer's option $\left(\mathrm{x}_{\mathrm{ij}}\right)$, regards to an existent solution from the market, which can be defined as a choice $i$, belonged to a certain type of appliance (energy service) $j$, to be acquired by the consumer. Considering the trade-offs referred before, together with the diversity of features, related to each solution, the consumer will deal with a problem of combinatorial nature, whose number of combinations are dependent on the number of options to be considered, regarding each dimension. The 20 million combinations (approximately) considered in this work, can be reduced, by considering that the consumer cannot perform any choices $\left(\mathrm{x}_{\mathrm{ij}}\right)$, given its limited budget.

Furthermore, and based on Table 1, all the equipment's, were pre-selected according to the number of occupants, in order to meet the consumer requirements (e.g. washing machine capacity, capacity of the fridge, etc.). Issues, such as air conditioner minimum capacity, minimum illuminance among others, was also considered here and compiled in a set of criteria (Figure1).

Additionally, it was also considered the influence of the consumer usage profile, regarding each potential solution/option $\mathrm{x}_{\mathrm{ij}}$, based on the assumptions presented on Table 2, for the case study considered.

Such assumptions have included the number of hours that each household appliance will perform for each day, which was then extrapolated for a monthly and yearly basis.

Table 2: Assumptions, according to consumer usage profile

\begin{tabular}{|c|c|c|c|c|}
\hline Emission factor $\left[\mathrm{gCO}_{2} / \mathrm{kWh}\right]$ & 674,6 & \multicolumn{2}{|c|}{$\begin{array}{c}\text { Discount Factor } \\
{[\%]}\end{array}$} & 7,0 \\
\hline $\begin{array}{l}\text { Life cycle (usage phase) } \\
\text { considered [years]: }\end{array}$ & 11 & \multicolumn{2}{|c|}{ Annual Factor } & 7,1 \\
\hline Electrical Energy tariff $[€ / \mathrm{kWh}]$ & 0,171 & & & \\
\hline \multirow{2}{*}{ Electrical appliance } & \multicolumn{4}{|c|}{ Profile of Usage (h) } \\
\hline & Day & Week & Month & Year \\
\hline Air Conditioning & 3 & 14 & 60 & 719 \\
\hline Dryer Machine & 1,2 & 8,4 & 32 & 361 \\
\hline (Electric) Oven & 7 & 7 & 31 & 360 \\
\hline Refrigerator & 11 & 76 & 333 & 3960 \\
\hline Lighting & 3,1 & 21 & 94 & 1080 \\
\hline Dish Washer Machine & 1,1 & 7,7 & 32 & 360 \\
\hline Washer Machine & 1,5 & 10,5 & 31 & 358 \\
\hline
\end{tabular}

These parameters have some influence on consumption, regarding each household appliance. Therefore, their savings, was achieved through the comparison of each efficient solution with the correspondent standard one. The consumer can also define its 
own profile of usage, according to its needs, or by using the profile, considered in this work, by default.

Regarding each individual efficient solution $\left(x_{i j}\right)$, it was determined the correspondent savings, $S_{\text {cons }_{i, j}}\left(x_{i j}\right)$ and $S_{i n v_{i, j}}\left(x_{i j}\right)$, respectively for the consumption and investment and regarding each option $i$, belonging to an appliance type $j$. Both savings, were obtained, based on the comparison between the efficient values of consumption and investment, and the correspondent standard solution (i.e. less efficient), regarding to an appliance/energy service type $j$. The value, resulted from this difference, was then discounted, according to the life cycle period (usage phase) considered, by applying a discount factor (Table 2).

Based on the approach, shown on Figure1, the decision variables are:

$$
x_{i j}: j(\text { appliancetype })=\{1 . .7\} \wedge i(\text { options })=\left\{1 . . n_{i}\right\}
$$

With the objective to maximize $V_{R}\left(x_{i j}\right)$, i.e.:

$$
\max V_{R}\left(x_{i j}\right): V_{R} \in \square \wedge x_{i j} \in\{0,1\}
$$

Based on work of [22], the value of $V_{R}$, can be achieved by:

$$
\begin{aligned}
& V_{R}^{(n)}=\sum_{i=1}^{20}\left(\frac{P_{\text {cons }_{i j}}\left(x_{i j}\right)}{P_{i n v_{i j}}\left(x_{i j}\right)}\right) \cdot \frac{I_{i n v . e f_{i j}}\left(x_{i j}\right)}{I_{\text {stdj }}} \cdot x_{i 1}+ \\
& +\sum_{i=1}^{11}\left(\frac{P_{\text {cons }_{i, 2}}\left(x_{i 2}\right)}{P_{i n v_{i, 2}}\left(x_{i 2}\right)}\right) \cdot \frac{I_{i n v . e f_{i j}}\left(x_{i 2}\right)}{I_{\text {total }}} \cdot x_{i 2}+\sum_{j=3}^{7} \sum_{i=1}^{10}\left(\frac{P_{\text {conn }_{i, j}}\left(x_{i j}\right)}{P_{i n v_{i, j}}\left(x_{i j}\right)}\right) \cdot \frac{I_{i n v . e f_{i j}}\left(x_{i j}\right)}{I_{s t d j}} \cdot x_{i j}
\end{aligned}
$$

Given that only one option $i$, can be chosen, regarding each appliance, the correspondent constraints are:

$$
\begin{gathered}
R_{1}\left(x_{i 1}\right): \sum_{i=1}^{20} x_{i 1}=1 \wedge x_{i 1} \in \square, \forall i=\{1 . .20\} \wedge x_{i 1}=\{0,1\} \\
R_{2}\left(x_{i 2}\right): \sum_{i=1}^{11} x_{i 2}=1 \wedge x_{i 2} \in \square, \forall i=\{1 . .11\} \wedge x_{i 2}=\{0,1\} \\
R_{k}\left(x_{i j}\right): \sum_{i=1}^{10} x_{i j}=1 \wedge k=\{3 . .7\} \wedge x_{i j}=\{0,1\}, \forall i=\{1 . .10\}, j=\{3 . .7\}
\end{gathered}
$$

The budget constraint, can be modeled by using the total investment (budget) and according to the following expression:

$$
R_{8}\left(x_{i j}\right): I_{\text {total }}\left(x_{i j}\right)=\sum_{i=1}^{20} x_{i 1} * I_{e f_{i 1}}+\sum_{i=1}^{11} x_{i 2} * I_{e f_{i 2}}+\sum_{j=3}^{7} \sum_{i=1}^{10} x_{i j} * I_{e f_{i j}} \quad I_{\text {total }} \in \square
$$

On Figure2, it's presented the EA's individual framework.

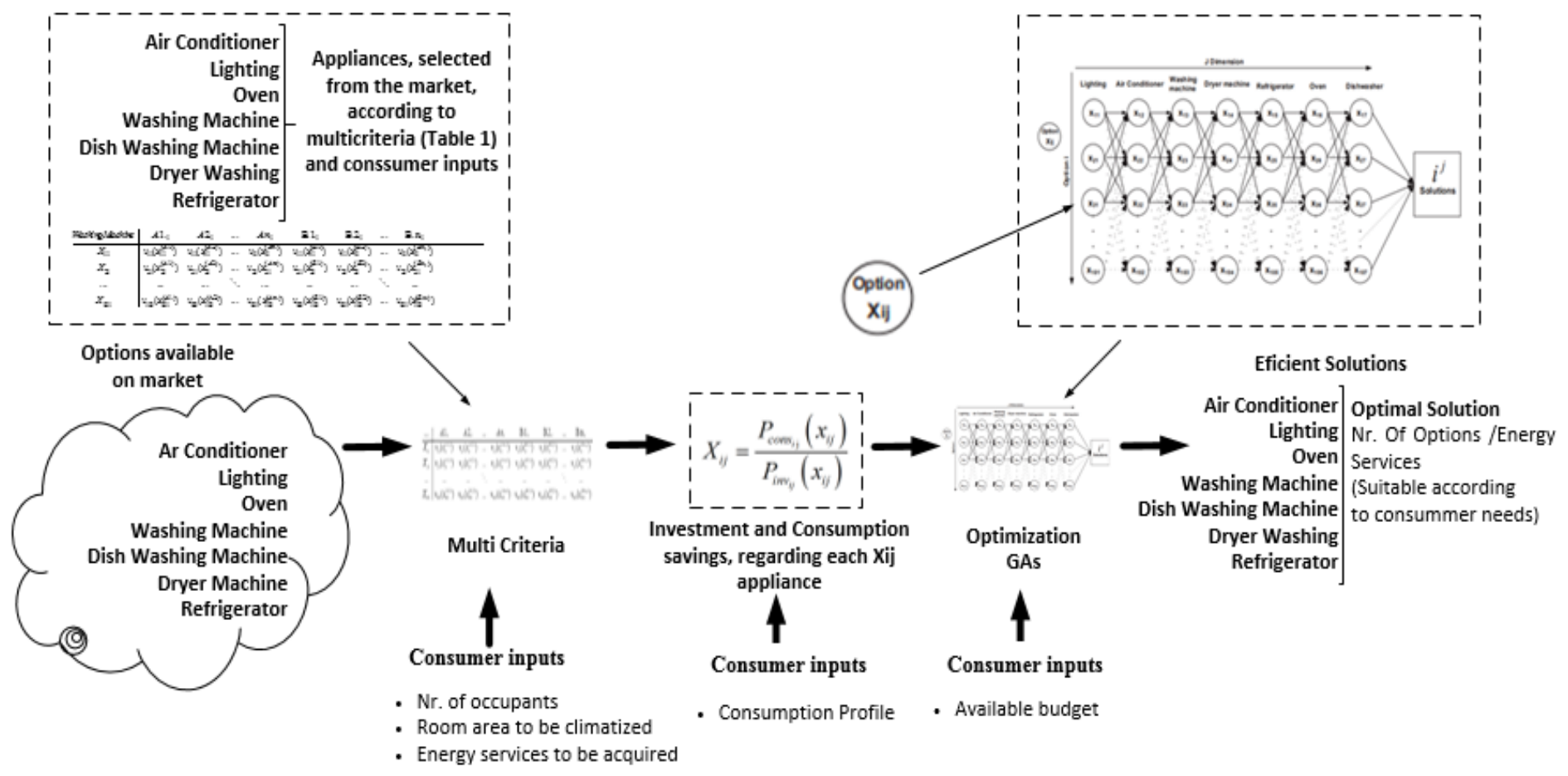

Figure 1(a): $1^{\text {st }}$ Approach - Single objective approach

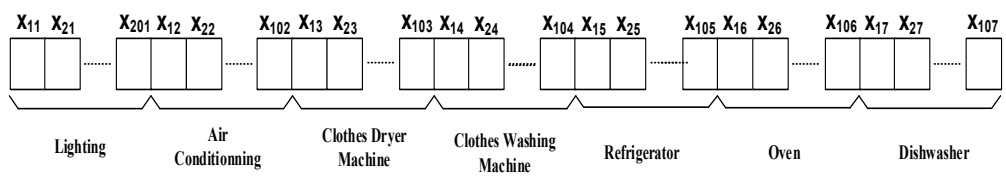

Figure 1(b): EA's individual framework (single objective approach) 
Table 3. Definition of the problem dimensions, according to each energy service considered and criteria used

\begin{tabular}{|c|c|c|c|c|c|c|}
\hline \multirow{2}{*}{$\begin{array}{l}\text { Energy } \\
\text { Service }\end{array}$} & Dimension & \multirow{2}{*}{ Ref. } & \multirow{2}{*}{$\begin{array}{c}\text { Dimension } \\
\text { B-Social } \\
\end{array}$} & \multirow{2}{*}{ Ref. } & Dimension & \multirow{2}{*}{ Ref. } \\
\hline & A-Economics & & & & C-Environment & \\
\hline \multirow{2}{*}{ Ilu-lighting } & $\begin{array}{l}\text { Energy Efficiency } \\
\text { Classification }\end{array}$ & Ilu.A1 & Durability (h) & Пาน.B1 & $\begin{array}{c}\text { Core Emissions (Life } \\
\text { Cycle-Usage Phase) } \\
{[\mathrm{kg}]}\end{array}$ & IluCl \\
\hline & $\begin{array}{c}\text { Energy Cons. Savings } \\
\text { (Life Cycle-Usage } \\
\text { phase) [E] }\end{array}$ & Ilu.A5 & $\begin{array}{l}\text { Color Rendering } \\
\text { Index (CRI) [\%] }\end{array}$ & Пาu.BS & $\begin{array}{c}\text { Cose Emissions (Life } \\
\text { Cycle-Production } \\
\text { Phase) [kg] }\end{array}$ & Iluc3 \\
\hline \multirow{2}{*}{$\begin{array}{l}\mathrm{AC}-\mathrm{Air} \\
\text { Conditioner }\end{array}$} & $\begin{array}{c}\text { Energy Efficiency } \\
\text { Classification } \\
\text { (Heating) }\end{array}$ & AC.A1 & Noise (Indoor) [dB] & ACB1 & $\begin{array}{c}\text { Cose Emissions (Life } \\
\text { Cycle-Production } \\
\text { Phase) [kg] }\end{array}$ & $\mathrm{ACC} 1$ \\
\hline & $\begin{array}{l}\text { Energy Efficiency } \\
\text { labelling (Cooling) }\end{array}$ & AC.A6 & $\begin{array}{l}\text { Customer Service } \\
\text { (warrant) }\end{array}$ & $\mathrm{ACB} 9$ & $\begin{array}{c}\text { Cose Emissions (Life } \\
\text { Cycle-Usage Phase) } \\
{[\mathrm{kg}]}\end{array}$ & $\mathrm{AC} \cdot \mathrm{C} 3$ \\
\hline$\ldots$ & $\ldots$ & $\ldots$ & $\ldots$. & $\ldots$ & $\ldots$ & $\ldots$ \\
\hline \multirow{3}{*}{$\begin{array}{l}\text { FE.-Oven } \\
\text { (Electric) }\end{array}$} & $\begin{array}{l}\text { Energy Efficiency } \\
\text { Classification }\end{array}$ & FE.A.1 & $\begin{array}{c}\text { COze Emissions (Life } \\
\text { Cycle-End Use } \\
\text { Phase) [kg] }\end{array}$ & FE.B1 & $\begin{array}{c}\text { Cose Emissions (Life } \\
\text { Cycle-Usage Phase) } \\
{[\mathrm{kg}]}\end{array}$ & FE.C.1 \\
\hline & 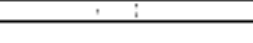 & 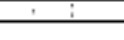 & & 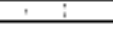 & & i \\
\hline & Investment cost [E] & FE.A.5 & $\begin{array}{c}\text { COre Emissions (Life } \\
\text { Cycle-End Use } \\
\text { Phase) [kg] }\end{array}$ & FE.B.5 & $\begin{array}{c}\text { Cose Emissions (Life } \\
\text { Cycle-End Use } \\
\text { Phase) [kg] }\end{array}$ & FE.C.3 \\
\hline \multirow{3}{*}{$\begin{array}{c}\text { MLL- } \\
\text { Dishwasher }\end{array}$} & $\begin{array}{l}\text { Energy Efficiency } \\
\text { Classification }\end{array}$ & MLL.A.1 & $\begin{array}{c}\text { Water Consumption } \\
\text { (Life Cycle-Usage } \\
\text { phase) }\end{array}$ & MLL.B.1 & $\begin{array}{c}\text { Cose Emissions (Life } \\
\text { Cycle-Usage phase) } \\
\text { [l] }\end{array}$ & MLL.C.1 \\
\hline & $\begin{array}{l} \\
\end{array}$ & i & 1 & i & $\begin{array}{l} \\
\end{array}$ & $i^{2}$ \\
\hline & $\begin{array}{c}\text { Water Cons. Savings } \\
\text { (Life Cycle-Usage } \\
\text { phase) [E] }\end{array}$ & MLLA. 6 & $\begin{array}{l}\text { Customer Service } \\
\text { (warrant) }\end{array}$ & MLL.B.6 & $\begin{array}{c}\text { Water Consumption } \\
\text { (Life Cycle-Usage } \\
\text { phase) [1] }\end{array}$ & MLL.C.4 \\
\hline
\end{tabular}

\section{3. $2^{\text {nd }}$ Approach - Multiobjective model involving 2 dimensions}

The $2^{\text {nd }}$ Approach, was pretended to study the interaction between 2 of the three existed dimensions, regarding sustainability, namely Economics vs Social Wellbeing and Economics vs Environment Wellbeing. To do this, it was included the formulation presented and studied before, regarding economic wellbeing, and the two other dimensions, by recurring to Multiatribute Value Theory (MAVT). This was preformed, in order to convert the objective function (3) (Economic Wellbeing) into a correspondent one, without units involved, to be added further into the other dimensions (Social and/or Environmental). After, the tests performed with multiobjective approach (2 dimensions), we have combined the three objective functions, regarding the three dimensions referred before, into one objective function, to achieve sustainable results, regarding the three dimensions. The assumptions presented before, were the same as well as the case study to apply the approach.

The criteria adopted here, are also the same, although there is the possibility of being changed, based on the number of occupants, existed in the building.

As it referred before, such pre-selection allows to reduction of the decision space, by considering only the available solutions, adjusted to the needs of the consumer. Such pre-selection, contributes also to rise the efficiency of NSGAII, by getting optimal solutions within less time. To pursue this, the proposed approach, has been developed by starting to consider at first 2 and then, the 3 dimensions of the problem. Both cases, are based on the approach described on Figure 2.

Each potential solution $\left(x_{i j}\right)$, is regarded from an option $i$, which is correspondent to the energy service $j$ to be bought by the consumer from the market. Like the first approach, the consumer's consumption profile (Table 2), was considered, in order to preform Life Cycle Cost Assessment (LCCA) to achieve for each appliance, the corresponding savings, in terms of water consumption $\left(S_{H 20 . \text { Cons }_{i, j}}\left(x_{i j}\right)\right.$ ), energy consumption $\left(S_{E . \text { Cons }_{i, j}}\left(x_{i j}\right)\right.$ ) and initial investment $\left(S_{i n n_{i, j}}\left(x_{i j}\right)\right.$ ). All these savings, have been obtained from the comparison between the more efficient solution and the less efficient one ("standard" solution).

By considering several factors, regarding each appliance, as well as the consumer's social, environmental and economic 
R.S. Santos et al. / Advances in Science, Technology and Engineering Systems Journal Vol. 5, No. 2, 399-410 (2020) concerns, a set of criteria was established based on the consumer preferences, 


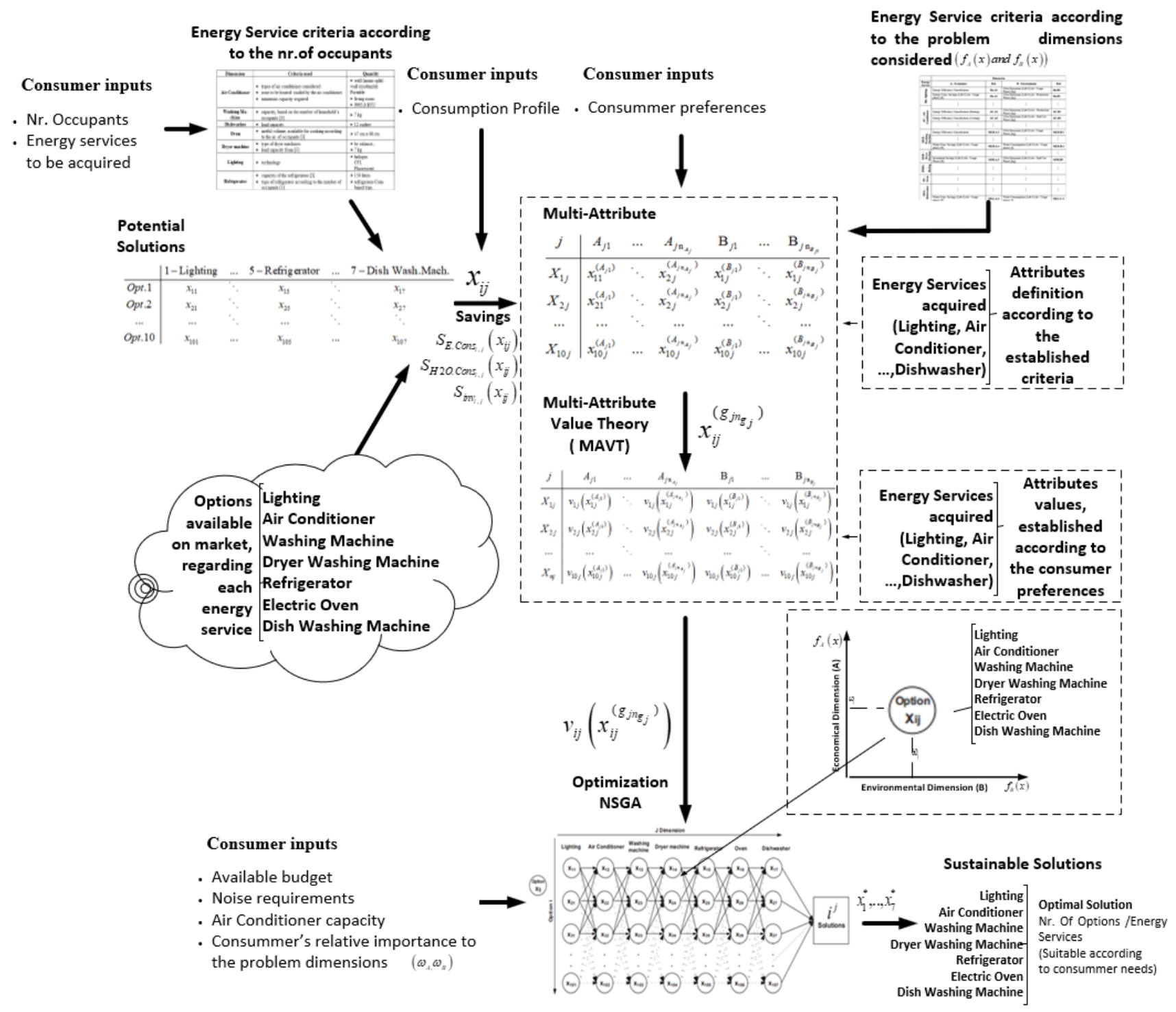

Figure 2: $2^{\text {nd }}$ Proposed approach - Multiobjective approach with MAVT

\begin{tabular}{c|cccccccccccc}
$A . C$. & $A_{21}$ & $A_{22}$ & $\ldots$ & $A_{2 n_{A_{2}}}$ & $B_{21}$ & $B_{22}$ & $\ldots$ & $B_{2 n_{B_{2}}}$ & $C_{21}$ & $C_{22}$ & $\ldots$ & $C_{2 n_{C_{2}}}$ \\
\hline$X_{12}$ & $x_{12}^{\left(A_{21}\right)}$ & $x_{12}^{\left(A_{22}\right)}$ & $\ldots$ & $x_{12}^{\left(A_{2 n_{12}}\right)}$ & $x_{12}^{\left(B_{21}\right)}$ & $x_{12}^{\left(B_{22}\right)}$ & $\ldots$ & $x_{12}^{\left(B_{2 n_{B 2}}\right)}$ & $x_{12}^{\left(C_{21}\right)}$ & $x_{12}^{\left(C_{22}\right)}$ & $\ldots$ & $\left.x_{12}^{\left(C_{2 n} C_{2}\right.}\right)$ \\
$X_{22}$ & $x_{22}^{\left(A_{21}\right)}$ & $x_{22}^{\left(A_{22}\right)}$ & $\ldots$ & $x_{22}^{\left(A_{2 n_{12}}\right)}$ & $x_{22}^{\left(B_{21}\right)}$ & $x_{22}^{\left(B_{22}\right)}$ & $\ldots$ & $x_{22}^{\left(B_{2 n_{B}}\right)}$ & $x_{22}^{\left(C_{21}\right)}$ & $x_{22}^{\left(C_{22}\right)}$ & $\ldots$ & $x_{22}^{\left(C_{2 n}\right)}$ \\
$\ldots$ & $\ldots$ & $\ldots$ & $\ddots$ & $\ldots$ & $\ldots$ & $\ldots$ & $\ldots$ & $\ldots$ & $\ldots$ & $\ldots$ & $\ldots$ & $\ldots$ \\
$X_{102}$ & $x_{102}^{\left(A_{21}\right)}$ & $x_{102}^{\left(A_{22}\right)}$ & $\ldots$ & $x_{102}^{\left(A_{2 n_{12}}\right)}$ & $x_{102}^{\left(B_{21}\right.}$ & $x_{102}^{\left(B_{22}\right)}$ & $\ldots$ & $x_{102}^{\left(B_{2 n_{B 2}}\right)}$ & $x_{102}^{\left(C_{21}\right)}$ & $x_{102}^{\left(C_{22}\right)}$ & $\ldots$ & $x_{102}^{\left(C_{2 n} n_{2}\right)}$
\end{tabular}

a)

\begin{tabular}{|c|c|c|c|c|c|c|c|c|c|c|c|c|}
\hline A.C. & $A_{21}$ & $A_{22}$ & $\ldots$ & $A_{2 n_{A_{2}}}$ & $B_{21}$ & $B_{22}$ & $\ldots$ & $B_{2 n_{B_{2}}}$ & $C_{21}$ & $C_{22}$ & $\ldots$ & $C_{2 n_{C_{2}}}$ \\
\hline$X_{12}$ & $v_{12}\left(x_{12}^{\left(A_{21}\right)}\right)$ & $v_{12}\left(x_{12}^{\left(A_{22}\right)}\right)$ & $\cdots$ & $v_{12}\left(x_{12}^{\left(A_{2 n_{A_{2}}}\right)}\right)$ & $v_{12}\left(x_{12}^{\left(B_{21}\right)}\right)$ & $v_{12}\left(x_{12}^{\left(B_{22}\right)}\right)$ & $\ldots$ & $v_{12}\left(x_{12}^{\left(B_{2 n_{B_{2}}}\right)}\right)$ & $v_{12}\left(x_{12}^{\left(C_{21}\right)}\right)$ & $v_{12}\left(x_{12}^{\left(C_{22}\right)}\right)$ & $\ldots$ & $v_{12}\left(x_{12}^{\left(C_{2 n C_{2}}\right)}\right)$ \\
\hline$X_{22}$ & $v_{22}\left(x_{22}^{\left(A_{21}\right)}\right)$ & $v_{22}\left(x_{22}^{\left(A_{22}\right)}\right)$ & $\cdots$ & $v_{22}\left(x_{22}^{\left(A_{2 n_{12}}\right)}\right)$ & $v_{22}\left(x_{22}^{\left(B_{21}\right)}\right)$ & $v_{22}\left(x_{22}^{\left(B_{22}\right)}\right)$ & $\cdots$ & $v_{22}\left(x_{22}^{\left(B_{2 n_{B_{2}}}\right)}\right)$ & $v_{22}\left(x_{22}^{\left(C_{21}\right)}\right)$ & $v_{22}\left(x_{22}^{\left(C_{22}\right)}\right)$ & $\cdots$ & $v_{22}\left(x_{22}^{\left(C_{2 n} C_{2}\right)}\right)$ \\
\hline ... & $\ldots$ & ... & $\ddots$ & ... & ... & ... & $\ldots$ & $\cdots$ & ... & $\cdots$ & $\ldots$ & $\cdots$ \\
\hline$X_{102}$ & $v_{102}\left(x_{102}^{\left(A_{21}\right)}\right)$ & $v_{102}\left(x_{102}^{\left(A_{22}\right)}\right)$ & $\ldots$ & $v_{102}\left(x_{102}^{\left(A_{2 n_{d_{2}}}\right)}\right)$ & $v_{102}\left(x_{102}^{\left(B_{21}\right)}\right)$ & $v_{102}\left(x_{102}^{\left(B_{22}\right)}\right)$ & $\ldots$ & $v_{102}\left(x_{102}^{\left(B_{2 B_{B_{2}}}\right)}\right)$ & $v_{102}\left(x_{102}^{\left(B_{21}\right)}\right)$ & $v_{102}\left(x_{102}^{\left(C_{22}\right)}\right)$ & $\cdots$ & \\
\hline
\end{tabular}

b)

Figure 3: Example of evaluation table regarding the Air Conditioning appliance's type: (a) $x_{j}^{\left(g_{j t}\right)}$; (b) $v_{i j}\left(x_{j}^{\left(g_{j t}\right)}\right)$. 


\section{R.S. Santos et al. / Advances in Science, Technology and Engineering Systems Journal Vol. 5, No. 2, 399-410 (2020)}

regarding each energy service, for the three problem dimensions, i.e., A-Economics, B-Social and C- Environment.

Some of these attributes, are described on Table 3. Then, and based on such attributes, MAVT was used to assist the consumer, by evaluating a set of alternative solutions, obtaining therefore, a set of evaluation tables, each one regarding to an energy service. On Figure 3, it's described an example, regarding a table, correspondent to the energy service "Air Conditioning".

Through the value attributes, obtained by using MAVT, it was used the additive model to aggregate all the evaluation tables. Such model has resulted into 3 different objective functions, regarding each one, to a sustainability's dimension of the problem. The three objective functions considered above, were further optimized, by recurring to an optimization algorithm, based on NSGAII.

As it referred on previous sections, the problem presented here, is from the type of combinatorial nature, whose number of combinations, is related to the dimension of the sample. In this work, it was considered 10 alternatives per energy service.

However, the combinations' number was reduced, since that, the consumer cannot make any choices, given its budget.

Other constraints were also accounted in this work, namely the appliances noise maximal requirements and the air conditioner capacity. Thus, and after being applying MAVT, the problem stated in this work, can be modeled as follows:

$$
\begin{array}{lc}
\max & V_{D}(x), \\
\text { s.t } x \in X & c / D=A, B, C \\
& c / V_{D}(x)=\left[V_{A}(x), V_{B}(x), V_{C}(x)\right]^{T}
\end{array}
$$

Where $\mathrm{x}$, is the vector of decision, i.e.:

$$
x \in X: x \in\left\{x_{i j}^{\left(A_{j i}\right)}, x_{i j}^{\left(\mathrm{B}_{j i}\right)}, x_{i j}^{\left(C_{j t}\right)}\right\} \wedge \mathrm{t}, \mathrm{i}, j \in \square
$$

with,

$$
\begin{aligned}
i & =\{1,2, . ., 10\} \wedge j=\{1,2,3, . ., 7\} \wedge \\
\wedge t & =\left\{\left\{1, . ., n_{A_{j}}\right\} \cup\left\{1, . ., n_{B_{j}}\right\} \cup\left\{1, . ., n_{C_{j}}\right\}\right\} \wedge n_{A_{j}}, n_{B_{j}}, n_{C_{j}} \in \square
\end{aligned}
$$

The $V_{A}(x), V_{B}(x)$ and $V_{C}(x)$, defines the objective functions, considering each problem dimension, i.e.:

$$
V_{g}(x)=\sum_{j=1}^{n_{j}} \sum_{t=1}^{n_{g_{j}}} v_{j}\left(x_{j}^{\left(g_{j i}\right)}\right) w / g=\{A, B, C\} \wedge v_{j}\left(x_{j}^{\left(g_{j t}\right)}\right) \wedge n_{j}, n_{g_{j}}, \mathrm{t}, j \in \square
$$

Therefore, the objective functions are:

$$
\begin{gathered}
\text { Economic Well-being: } \max V_{A}(x)=\sum_{j=1}^{n_{j}} \sum_{t=1}^{n_{A_{j}}} v_{j}\left(x_{j}^{\left(A_{j l}\right)}\right) \\
\text { Social Well - being: } \max V_{B}(x)=\sum_{j=1}^{n_{j}} \sum_{t=1}^{n_{B_{j}}} v_{j}\left(x_{j}^{\left(\mathrm{B}_{j}\right)}\right) \\
\text { Environment Well - being }: \max V_{B}(x)=\sum_{j=1}^{n_{j}} \sum_{t=1}^{n_{B_{j}}} v_{j}\left(x_{j}^{\left(\mathrm{B}_{j l}\right)}\right)
\end{gathered}
$$

The $1^{\text {st }}$ objective function, were based on previous work [9].

The following approaches (with 2 and 3 objectives), uses the additive model based on MAVT, to obtain an unique objective function, based on the 2 and 3 objective functions (according to the approach used) pondered by the consumer's concern $\left(\omega_{g}\right)$, i.e.:

$$
\begin{aligned}
& V\left(V_{A}(x), V_{B}(x)\right)=\omega_{A} \cdot V_{A}(x)+\omega_{B} \cdot V_{B}(x)+\omega_{C} \cdot V_{C}(x)= \\
& \quad=\sum_{j=1}^{n_{j}}\left(\omega_{A} \sum_{t=1}^{n_{A_{j}}} v_{j}\left(x_{j}^{\left(A_{j}\right)}\right)+\omega_{B} \sum_{t=1}^{n_{B_{j}}} v_{j}\left(x_{j}^{\left(\mathrm{B}_{j i}\right)}\right)+\omega_{C} \sum_{t=1}^{n_{C_{j}}} v_{j}\left(x_{j}^{\left(C_{j i}\right)}\right)\right)
\end{aligned}
$$

The constraints, regarding economic and environment wellbeing/dimensions, are:

Available Budget $\left(\eta_{\text {avail }}\right)$ :

$$
r_{1}: \sum_{j=1}^{n_{\text {dim }}} I_{j}\left(x_{j}\right) \leq \eta_{\text {avail. }} \Leftrightarrow \sum_{j=1}^{n_{\text {dim }}} x_{j}^{\left(A_{j t}\right)} \leq \eta_{\text {avail. }}
$$

With

$$
A_{\mathrm{j} t}=\left\{A_{14}, A_{26}, A_{35}, A_{44}, A_{54}, A_{64}, A_{75}\right\} \wedge n_{\text {dim }}, \mathrm{t}, j \in \square
$$

Environment-Noise:

$$
r_{j} \text { :Noise }_{j} \leq \text { Max.Noise }_{j} \Leftrightarrow x_{j}^{\left(B_{j t}\right)} \leq \text { Max.Noise }_{j}
$$

With:

$$
B_{\mathrm{j} t}=\left\{B_{24}, B_{35}, B_{44}, B_{54}, B_{64}, B_{75}\right\} \wedge n_{\mathrm{dim}}, \mathrm{t}, j \in \square
$$

The NSGAII individual framework, presented on Figure 4, regards the approach for the 2 and 3 dimensions of sustainability presented next. For the approach with 2 dimensions, the structure is the same, although considering only 2 dimensions each.

Instead of binary codification, regarding the $1^{\text {st }}$ approach (one objective), NSGAII's codification have used real one. The model, developed here, will be deployed, by using the case study referred before, on previous section.

\section{Results \& Discussion}

\section{1. $1^{\text {st }}$ Approach - Single objective model}

Based on what was referred before, the $1^{\text {st }}$ approach, has consisted into an EA's single objective approach, whose codification used, was binary, to ensure the existence of a unique individual solution at a time, and regarding appliance's type.

The approach presented here, was implemented by using MATLAB software, given its efficiency when dealing with data, which are organized into matrices. Our previous work ([1]) has allowed us to improve our EA's behavior by testing different objective functions, as well as different parameters values. To assess the quality of EA's solutions, it was used Simplex, which was implemented by using General Algebraic Modeling System (GAMS) software.

The best formulation, achieved at the time from ([1]), was the one presented on previous section. The results, presented next, were achieved, by using the following parameters: 


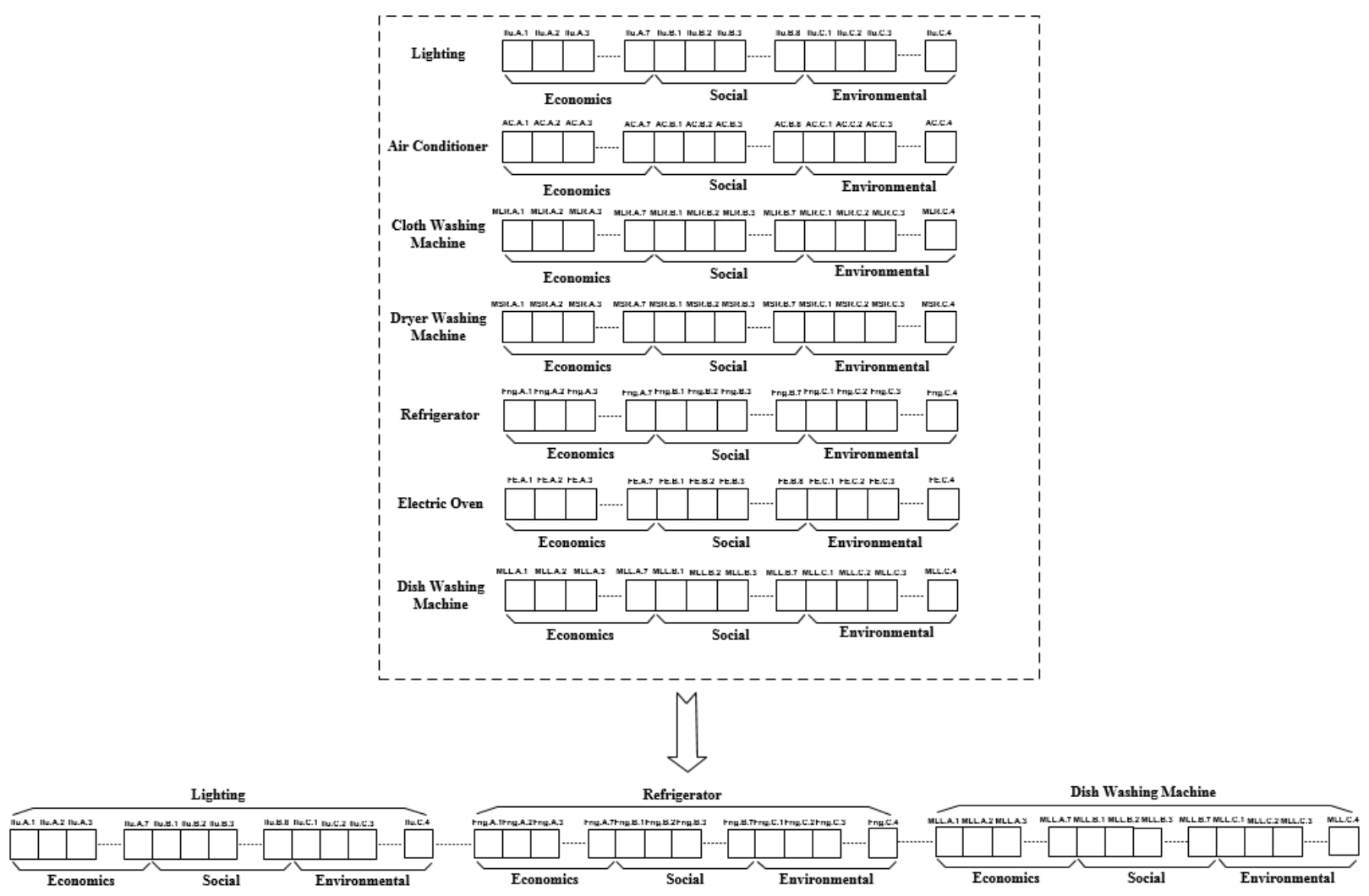

Figure 4: Individual framework (regarding the 2 and 3 objective approachs)

- Population size: 130

- Selection technique: roulette method

- Crossover technique: double point

- Crossover ratio: 0,55

- Mutation technique: bit string

- Mutation ratio: 0,02

- Convergence ratio: 0,002

- Maximum number of iterations/generations: without limits

On previous work ([1]), it was assessed the best fitness function (and objective function), based on the average values of the correspondent $\mathrm{V}_{R}^{(\mathrm{n})}$ objective, by preforming 12 runs/budget.

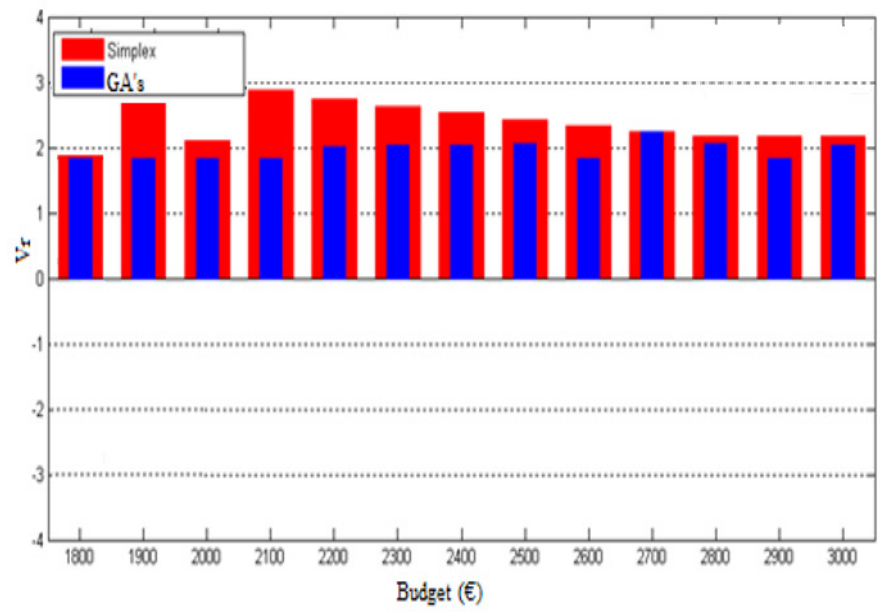

Figure 5: Average values of $\mathrm{Vr}$, considering each value of budget constraint scenario
The EA's behavior, regarding the exploitation of feasible region, was also exploited, by using budget scenario constraint (eq. (7)). Although SIMPLEX, provides the best values, GAs, can also provide good solutions, considering the proximity of both values, By considering the present objective function, EA was also more efficient (on average) than other fitness functions assessed and studied on [1][14]. On Fig.5, it's presented also the average values of $\mathrm{Vr}$ (objective/fitness function), regarding the present formulation and considering both methods; GAs and SIMPLEX.

Although SIMPLEX, provides the best values, GAs, can also provide good solutions, considering the proximity of both values, regarding each budget constraint scenario.

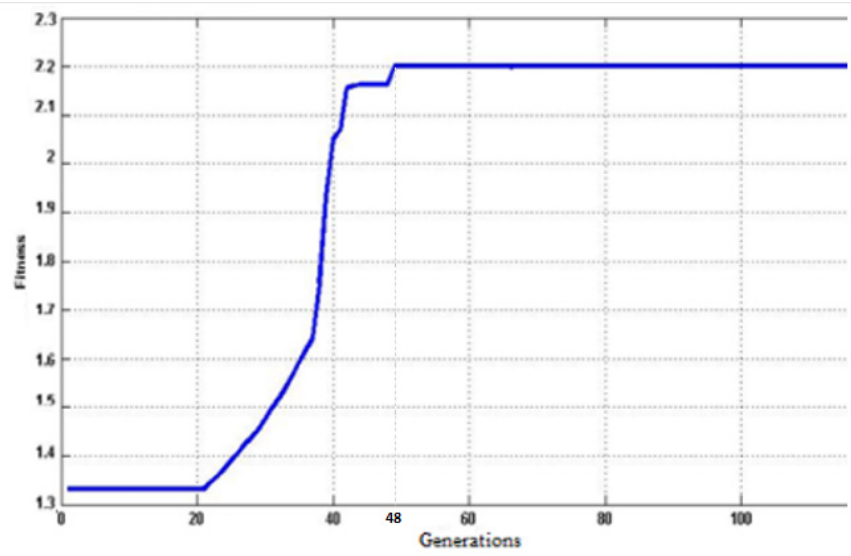

Figure 6: Example of fitness evolution from the best individual/generation (budget scenario of $1900 €$ ) 


\section{R.S. Santos et al. / Advances in Science, Technology and Engineering Systems Journal Vol. 5, No. 2, 399-410 (2020)}

The performance of GAs is shown on Figure 6, considering a $1900 €$ budget constraint scenario. On average, the steady state was achieved with 51 generations and considering 12 runs/budget constraint scenario.

On Table 4, it's described a feasible solution achieved with the approach described in this study, regarding a budget scenario constraint of 2700 Euros.

It is also shown the $\mathrm{CO}_{2}$ avoided emissions (i.e. savings), regarding this solution, by comparing it with the less efficient.

Furthermore, the consumer has the information about what brand and model, regarding each appliance type to be acquired, as well as other information, such as the life cycle of each equipement and the savings in terms of electrical energy consumption, by comparying an eficient appliance with a less eficient one.

Table 4. Solution achieved by using EA's approach

\begin{tabular}{|c|c|c|c|c|c|c|c|c|}
\hline Dimension & 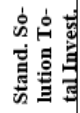 & 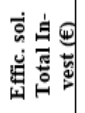 & 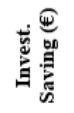 & 焉 & 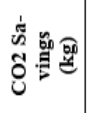 & 苟总 & 蔔 & 丞 \\
\hline Lighting & 15,89 & 10,55 & 5,34 & 58,44 & 28,50 & $8000 \mathrm{~h}$ & Philips & $\begin{array}{c}\text { GENIE } \\
\text { ESAVER } \\
11 W / 827 \\
\end{array}$ \\
\hline $\begin{array}{l}\text { Air Condi- } \\
\text { tioning }\end{array}$ & 368,0 & 299,0 & 69,00 & 1315,60 & 1315,57 & $10 \mathrm{yrs}$ & Electro & $\begin{array}{c}\text { TC } \\
\text { N12KRH } \\
\text { PORT }\end{array}$ \\
\hline $\begin{array}{l}\text { Refrigera- } \\
\text { tor }\end{array}$ & 250,0 & 529,0 & $-279,0$ & 704,11 & 8,50 & $10 \mathrm{yrs}$ & Indesit & TAN13FFS \\
\hline $\begin{array}{c}\text { Dishwasher } \\
\text { Machine }\end{array}$ & 310,0 & 349,0 & $-39,00$ & 3,20 & 6,20 & $10 \mathrm{yrs}$ & Fagor & 1LF-011S \\
\hline $\begin{array}{l}\text { Washing } \\
\text { Machine }\end{array}$ & 262,0 & 294,0 & $-32,00$ & 6,85 & 94,80 & $10 \mathrm{yrs}$ & Zanussi & FLN1009 \\
\hline Oven & 170,0 & 199,0 & $-29,00$ & 1,30 & 2,60 & $10 \mathrm{yrs}$ & Candy & FST100X \\
\hline $\begin{array}{l}\text { Clothes } \\
\text { dryer }\end{array}$ & 349,0 & 419,0 & $-70,00$ & 11,32 & 1,800 & $10 \mathrm{yrs}$ & Indesit & 1SL79C \\
\hline Total: & 1724,9 & 2099,6 & $-374,7$ & 2100,80 & 1458,0 & - & - & - \\
\hline
\end{tabular}

Given the stochasticity of the GAs, as a metaheuristic method, it was made a statistical study to evaluate the consistency of the model, which was developed on previous works [1][13].

\section{2. $2^{\text {nd }}$ Approach - Multiobjective model}

In order to achieve sustainable solutions, and based on Section 4.3, a Multiobjective method, based on NSGAII (NonSorting Genetic Algorithm II) ([18]), was coded on Matlab, by accounting the NSGAII's parameters, regarding each NSGAII's phase, namely; selection (roulette), crossover (double point) and mutation (normal random). The other parameters (crossover, mutation rate and initial population) were established after several simulations. Parameters such as the crossover rate, the mutation rate and the population size (120 individuals), were also experimented. With regards to the stopping criteria, it was chosen a parameter value of 80 , as being the maximum number of iterations/generations allowed. It was considered several arrangements of crossover and mutation rates of NSGA-II, to obtain a suitable arrangement ( Table 5).
Table 5. Values, regarding the arrangements of crossover and mutation rates

\begin{tabular}{ccc}
\hline Experiment & $\begin{array}{c}\text { Crossover } \\
\text { Rate }\end{array}$ & $\begin{array}{c}\text { Mutation } \\
\text { Rate }\end{array}$ \\
\hline 1 & 0.75 & 0.15 \\
2 & 0.75 & 0.25 \\
3 & 0.85 & 0.15 \\
4 & 0.85 & 0.25 \\
\hline
\end{tabular}

Therefore, it was used the following NSGAII's parameters: population size of 120 individuals, a maximum number of 80 iterations, a mutation rate of 0,15 and a crossover rate of 0,75 .

In the Figure 7, it's shown the pareto frontier, for different arrangements of crossover and mutation rates.

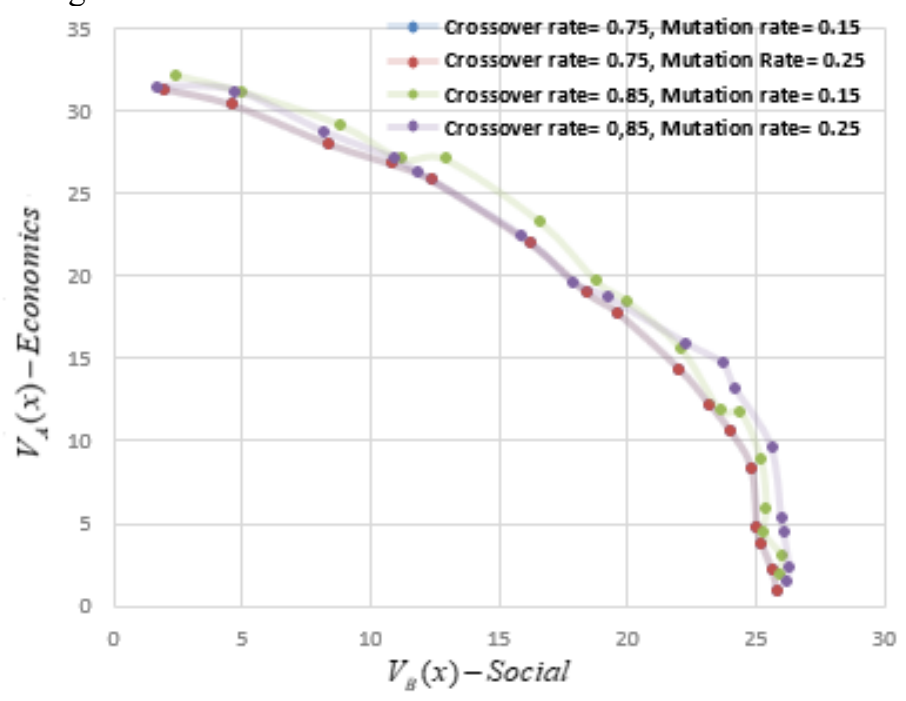

After the tuning with NSGAII's parameters, the Pareto frontier in Figure 9, was therefore achieved, with each one of the 16 nodes, representing an optimal solution of the problem. In other words, each node represents a set of individual solutions (appliances from the market), related each one, to an energy service.

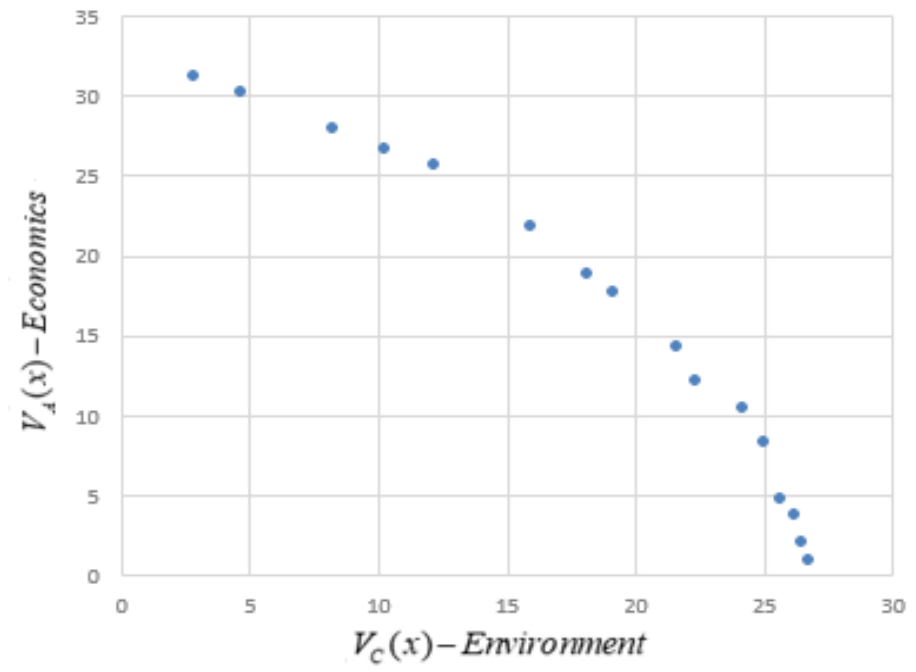

Figure 8. Pareto frontier (last generation) Economical vs Environmental

$$
\left(\omega_{\mathrm{A}}=0,73, \omega_{\mathrm{B}}=0,00, \omega_{\mathrm{C}}=0,27\right)
$$


Such calculations were performed, by considering a scenario where the consumer only considers the Economic and Environment concerns, i.e., $\omega_{\mathrm{A}}=0,73, \omega_{\mathrm{B}}=0,00$ and $\omega_{\mathrm{C}}=0,27$ (Figure 10).

The trade-off, existed between the two dimensions, can also be noted through Figure 8, since the reduction on economic wellbeing, leads to an increase of the environment well-being.

Table 6 , shows the results from one of the nodes achieved here, by assuming a budget constraint value of $2250 €$.

Table 6. Solution achieved: Economical vs Environmental $\left(\omega_{\mathrm{A}}=0,73, \omega_{\mathrm{B}}=0,00, \omega_{\mathrm{C}}=0,27\right)$

\begin{tabular}{|c|c|c|c|c|c|c|c|c|}
\hline Dimension & $\begin{array}{c}\text { Stand. } \\
\text { Solution } \\
\text { Total } \\
\text { Invest. } \\
(€)\end{array}$ & $\begin{array}{c}\text { Effic. } \\
\text { sol. } \\
\text { Total } \\
\text { Invest } \\
(€)\end{array}$ & $\begin{array}{c}\text { Invest. } \\
\text { Saving } \\
(€)\end{array}$ & $\begin{array}{c}\text { Consum. } \\
\text { Saving } \\
(€)\end{array}$ & $\begin{array}{c}\mathrm{CO}_{2} \\
\text { Savings } \\
(\mathbf{k g})\end{array}$ & $\begin{array}{c}\mathrm{H}_{2} \mathbf{0} \\
\text { Savings } \\
(\mathbf{l})\end{array}$ & Brand & Model \\
\hline Lighting & 15.89 & 09.53 & 5.34 & 59.40 & 28.90 & - & GE & EFL23W \\
\hline $\begin{array}{c}\text { Air } \\
\text { Conditioning }\end{array}$ & 368.00 & 299.00 & 69.00 & 1320.60 & 1322.60 & - & Whirlpool & PACW9HP \\
\hline Refrigerator & 250.00 & 529.00 & -279.00 & 708.10 & 8.70 & - & BECKEN & Bc2016 Ix \\
\hline $\begin{array}{c}\text { Dishwasher } \\
\text { Machine }\end{array}$ & 310.00 & 349.00 & -39.00 & 3.20 & 7.80 & 429.07 & Bosch & SMS25AI00E \\
\hline $\begin{array}{c}\text { Washing } \\
\text { Machine }\end{array}$ & 262.00 & 294.00 & -32.00 & 6.90 & 94.80 & 351.02 & INDESIT & EWE71252 W \\
\hline Oven & 170.00 & 199.00 & -29.00 & 1.70 & 2.33 & - & Zanussi & ZZB21601XV \\
\hline $\begin{array}{c}\text { Clothes } \\
\text { dryer }\end{array}$ & 349.00 & 419.00 & -70.0 & 12.30 & 1.82 & - & Electrolux & EDP2074PDW \\
\hline Total: & 1727.89 & 2098.53 & -374.66 & 2112.20 & 1466.95 & 780.09 & - & \\
\hline
\end{tabular}

Through the values, presented above, we can see that if the consumer, choses the optimal solutions provided by NSGAII, he can save 1737,54 $€$ approximately, having also $\mathrm{CO}_{2}$ and water savings. Both values are per year, for a life cycle of 10 years.

The same, were performed, by considering a scenario where the consumer only considers the Economic and Social concerns, i.e., $\omega_{\mathrm{A}}=0,73, \omega_{\mathrm{B}}=0,27$ and $\omega_{\mathrm{C}}=0,00$ (Figure 9).

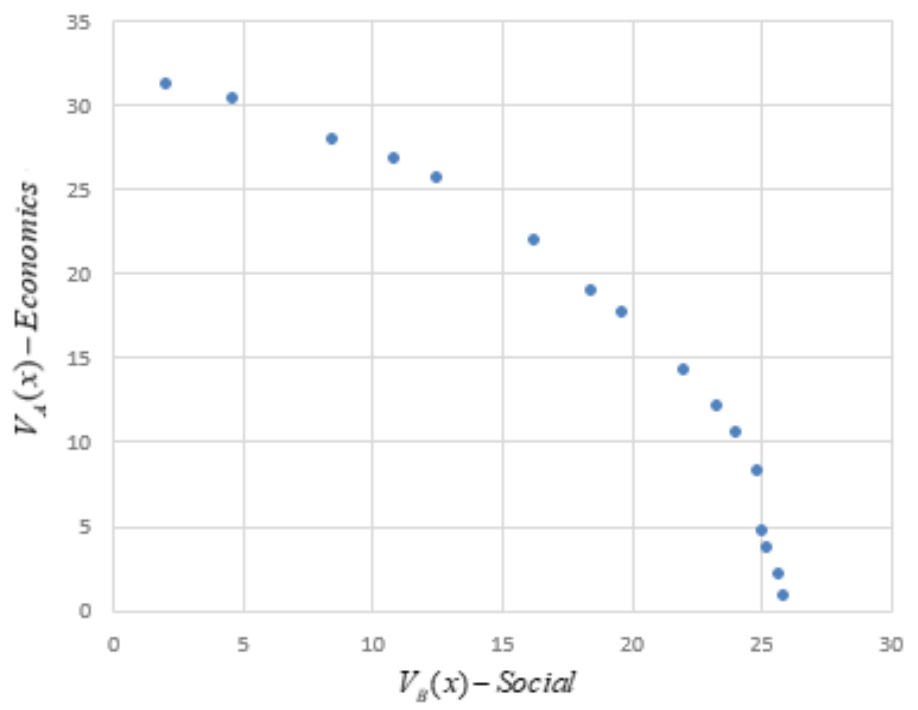

Figure 9. Pareto frontier regarding the last generation; Economical vs Social

$$
\left(\omega_{\mathrm{A}}=0,73, \omega_{\mathrm{B}}=0,27, \omega_{\mathrm{C}}=0,00\right)
$$

Through the last iteration/generation, it was obtained sixteen feasible solutions, achieving therefore, an example of a Pareto frontier. One of the nodes achieved with this scenario, is shown on Table 7, by considering a budget of $2250 €$ and a life cycle of 10 years.

Table 7. Solution achieved: Economical vs Social $\left(\omega_{\mathrm{A}}=0,73, \omega_{\mathrm{B}}=0,27, \omega_{\mathrm{C}}=0,00\right)$

\begin{tabular}{|c|c|c|c|c|c|c|c|c|}
\hline Dimension & $\begin{array}{c}\text { Stand. } \\
\text { Solution } \\
\text { Total } \\
\text { Invest. } \\
(€)\end{array}$ & $\begin{array}{c}\text { Effic. } \\
\text { sol. } \\
\text { Total } \\
\text { Invest } \\
(€)\end{array}$ & $\begin{array}{c}\text { Invest. } \\
\text { Saving } \\
(€)\end{array}$ & $\begin{array}{c}\text { Consum. } \\
\text { Saving } \\
(€)\end{array}$ & $\begin{array}{c}\mathrm{CO}_{2} \\
\text { Savings } \\
(\mathrm{kg})\end{array}$ & $\begin{array}{c}\mathrm{H}_{2} \mathbf{0} \\
\text { Savings } \\
(\mathbf{l})\end{array}$ & Brand & Model \\
\hline Lighting & 15.89 & 69.65 & 5.34 & 59.40 & 27.60 & - & OSRAM & 3316242 \\
\hline $\begin{array}{c}\text { Air } \\
\text { Conditioning }\end{array}$ & 352.00 & 279.00 & 69.00 & 1319.50 & 1322.60 & - & SAMSUNG & AQV09PSBN \\
\hline Refrigerator & 250.00 & 529.00 & -279.00 & 708.10 & 9.72 & - & Candy & CFET 6182W \\
\hline $\begin{array}{c}\text { Dishwasher } \\
\text { Machine }\end{array}$ & 320.10 & 351.99 & -38.10 & 2.20 & 6.90 & 423.02 & BALAY & 3 VS303IP \\
\hline $\begin{array}{c}\text { Washing } \\
\text { Machine }\end{array}$ & 262.00 & 294.00 & -32.00 & 6.90 & 95.10 & 317.04 & Siemens & WI12A222ES \\
\hline Oven & 171.00 & 701.00 & -28.30 & 2.82 & 2.33 & - & Electrolux & EZC2430AOX \\
\hline $\begin{array}{c}\text { Clothes } \\
\text { dryer }\end{array}$ & 368.00 & 449.00 & -68.00 & 10.20 & 1.82 & - & BOSCH & WTE84107EE \\
\hline Total: & 1738.99 & 2673,64 & 371.06 & 2109.12 & 1458.90 & 740.06 & - & - \\
\hline
\end{tabular}

According to the values on Table 7, the consumer can save up to $1738.06 €$, through the selection of the appliances mentioned above. Additionally, there also savings with $\mathrm{CO}_{2}$ and water as well, with both values being expressed as savings/years and based on the life cycle considered here.

Based on both trade-offs, presented above, it was considered a scenario with the tree dimensions and their correspondent consumer's relative importance, i.e., Economical vs Social vs Environmental $\left(\omega_{\mathrm{A}}=0,66, \omega_{\mathrm{B}}=0,23\right.$ and $\left.\omega_{\mathrm{C}}=0,11\right)$.

In order to pursue the main goal, referred before, it was performed a scenario where the consumer considers the 3 dimensions of sustainability, i.e., Economic, Social and Environment concerns, i.e.; $\omega_{\mathrm{A}}=0,66, \omega_{\mathrm{B}}=0,23$ and $\omega_{\mathrm{C}}=0,11$ (Figure 10).

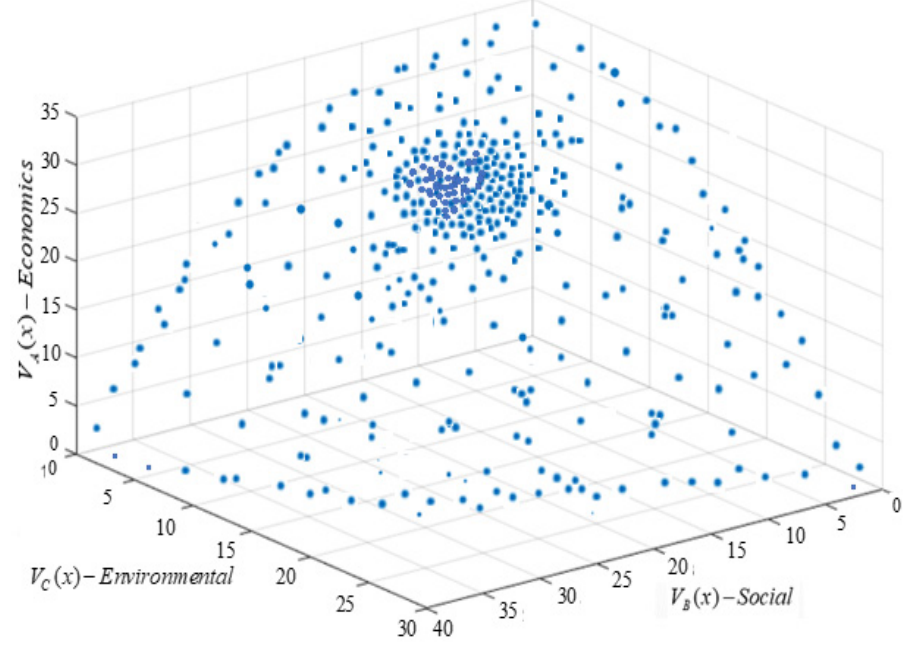


Through Figure10, it can be seen that the crowding distance, between the final solutions obtained, regarding the obtained Pareto surface, is higher in the region where the Economic dimension is more dominant. Such dominance order is followed by the Social, and at last, the Environmental dimension. Such dominance order, is somehow expected, given the relative importance's values (weight) considered in this case, and regarding each dimension considered, i.e.; $\omega_{\mathrm{A}}=0,66, \omega_{\mathrm{B}}=0,23$ and $\omega_{\mathrm{C}}=0,11$.

One of the nodes, represented on that surface, are shown on Table 8 , considering a budget of $2250 €$, for 10 years of life cycle.

Table 8. Example of a solution obtained from this approach. Economical vs Social vs Environmental $\left(\omega_{\mathrm{A}}=0,66, \omega_{\mathrm{B}}=0,23, \omega_{\mathrm{C}}=0,11\right)$

\begin{tabular}{|c|c|c|c|c|c|c|c|c|}
\hline Dimension & $\begin{array}{l}\text { Stand. } \\
\text { Solution } \\
\text { Total } \\
\text { Invest. } \\
\text { (€) }\end{array}$ & $\begin{array}{c}\text { Effic. } \\
\text { sol. } \\
\text { Total } \\
\text { Invest } \\
(€) \\
\end{array}$ & $\begin{array}{c}\text { Invest. } \\
\text { Saving } \\
(€)\end{array}$ & $\begin{array}{c}\text { Consum. } \\
\text { Saving } \\
(€)\end{array}$ & $\begin{array}{c}\mathrm{CO}_{2} \\
\text { Savings } \\
(\mathrm{kg})\end{array}$ & $\begin{array}{c}\mathrm{H}_{2} \mathrm{O} \\
\text { Savings } \\
\text { (I) }\end{array}$ & Brand & Model \\
\hline Lighting & 16.88 & 49.04 & 5.35 & 62.20 & 28.90 & - & Phillips & LEDspotMV \\
\hline $\begin{array}{c}\text { Air } \\
\text { Conditioning }\end{array}$ & 352.00 & 279.00 & 69.00 & 1319.50 & 1315.70 & - & SAMSUNG & AQV09PSBN \\
\hline Refrigerator & 234.00 & 399.00 & -265.00 & 709.30 & 9.72 & - & BECKEN & Bc2016 Ix \\
\hline $\begin{array}{l}\text { Dishwasher } \\
\text { Machine }\end{array}$ & 310.00 & 349.00 & -39.00 & 3.20 & 6.90 & 423.00 & Bosch & SMS25AI00E \\
\hline $\begin{array}{l}\text { Washing } \\
\text { Machine }\end{array}$ & 272.20 & 249.90 & -33.00 & 5.60 & 95.10 & 322.10 & INDESIT & EWE71252 W \\
\hline Oven & 171.00 & 701.00 & -28.30 & 2.82 & 2.20 & - & Electrolux & EZC2430AOX \\
\hline $\begin{array}{l}\text { Clothes } \\
\text { dryer }\end{array}$ & 368.00 & 449.00 & -68.00 & 10.20 & 1.70 & - & $\mathrm{BOSCH}$ & WTE84107EE \\
\hline Total: & 1724.80 & 2475.94 & -262.65 & 2112.30 & 1460.22 & 745.10 & - & - \\
\hline
\end{tabular}

According to Table 8, the consumer, can save up to 1849,65 $€$, avoiding approximately $1460,22 \mathrm{~kg}$ of $\mathrm{CO}_{2}$ and saving 745,10 liters of water, with both values expressed as savings/years, and based on 10 years as the life cycle considered in this study.

Through the performance of such scenarios, we can see some coherence with the application of $\omega_{\mathrm{A}}, \omega_{\mathrm{B}}$ and $\omega_{\mathrm{C}}$.

An example is the water savings achieved, where it is more noticed when the correspondent Environment weight $\left(\omega_{\mathrm{C}}\right)$, is increased.

\section{Conclusions \& Further Work}

This paper follows a research line, where the main goal is to present a method to provide sustainable electrical household appliances from the market to a household consumer. On previous work, and at a first stage, it was formulated a single objective problem, although considering only the environmental impacts $\left(\mathrm{CO}_{2}\right.$ savings) and the economic savings, each one, related to the initial investment and energy consumption. Both indicators, were calculated, by preforming the correspondent lifecycle cost assessment (LCCA) of each household appliance, and during the correspondent usage phase.

It was also used Genetic Algorithms (GAs) to achieve several and different feasible solutions, whose quality were tested through the comparison with the results achieved from simplex method.
Then, the approach was formulated by considering a multiobjective problem, although by exploring 2 dimensions at a time, and by recurring to MAVT and NSGA II methods

This approach has used a set of established criteria, in order to perform a pre-selection of candidate solutions existed on market, and suitable to the consumer needs. The purpose was to redefine the decision space, composed by a set of candidate solutions, and based on each type of household appliance considered to be acquired by the consumer.

Furthermore, it was adopted additional criteria, to be further integrated with MAVT, in order to achieve a model with the consumer preferences and based on the 3 problem dimensions presented.

The objective was to improve the consumer well-being, regarding each sustainability's dimension referred above, and based on their importance, given by the consumer.

When achieving the MAVT model, it was also included the ecological impact in terms of water and $\mathrm{CO}_{2}$ savings, as well as economic issues, such as energy consumption and initial investment savings, based on the lifecycle cost assessment (LCCA) of each household appliance. Social issues were also included, by integrating the consumer's preferences in terms of design, reliability and other issues, including even the visual and thermal comfort. Then NSGAII was applied, by achieving sustainable solutions from the market, that maximizes the tree dimensions referred before.

The approach presented here, also allows a consumer, to achieve a set of savings regarding issues such as; $\mathrm{CO}_{2}$ emissions, energy and water consumption.

As further work, this approach could be applied into other energy services/household appliances, for instance, with a relevant impact in terms of sustainable development (e.g. information technology's equipment's such as computers, printers, among others).

\section{References}

[1] R. Santos, J. C. O. Matias and A. Abreu, "An approach to provide efficient choices to a household consumer," 2019 International Young Engineers Forum (YEF-ECE), Costa da Caparica, Portugal, 2019, pp. 46-51. doi: 10.1109/YEF-ECE.2019.8740824

[2] IEA: Energy Efficiency 2017 - Market Reports Series, OECD/IEA (2017)

[3] Gul, M., Patidar. S. (2015). Understanding the energy consumption and occupancy of a multi-purpose academic building, In Energy and Buildings, Volume 87, Pages 155-165, ISSN 0378-7788

[4] ADENE: Manual da Etiqueta Energética, ADENE, Lisboa ISBN: 978-9728646-36-3 (2017)

[5] Wong, I., L., Krüger, E., Comparing energy efficiency labelling systems in the EU and Brazil: Implications, challenges, barriers and opportunities, In Energy Policy, vol.109, pp. 310-323, Springer, Heidelberg (2017)

[6] Fell, M.: Energy services: A conceptual review, Energy Research \& Social Science, vol.27, pp.129--140, Springer (2017)

[7] Hoxha, E., Jusselme, T. (2017), On the necessity of improving the environmental impacts of furniture and appliances in net-zero energy buildings, In Science of The Total Environment, Volumes 596-597, Pages 405-416, ISSN 0048-9697

[8] Ting, T.O.; Rao, M.V.; Loo, K.C. (2006) A novel approach for unit commitment problem via an effective hybrid particle swarm optimization. IEEE Trans. Power Syst., 21, 411-418.

[9] Ferreira, F.A.; Lemos, F.A.B. (2010) Unbalanced electrical distribution network reconfiguration using simulated annealing. In Proceedings of the 2010 IEEE/PES Transmission and Distribution Conference and Exposition: Latin America (T\&D-LA), Sao Paulo, Brazil, 8-10; pp. 732-737.

[10] Agrawal, P.; Rao, S. (2014), Energy-aware scheduling of distributed systems. IEEE Trans. Autom. Sci. Eng. , 11, 1163-1175. 
[11] Ko, M.J.; Kim, Y.S.; Chung, M.H.; Jeon, H.C.(2015), Multi-objective design for a hybrid energy system using genetic algorithm. Energies, 8, 2924-2949.

[12] Randall, M., Rawlins, T., Lewis, A., Kipouros, T., Performance Comparison of Evolutionary Algorithms for Airfoil Design, In Procedia Computer Science, vol. 51, pp. 2267-2276, Springer Heidelberg (2015)

[13] R.S. Santos, J.C.O. Matias, A. Abreu, F. Reis, Evolutionary algorithms on reducing energy consumption in buildings: An approach to provide smart and efficiency choices, considering the rebound effect, Computers \& Industrial Engineering, Volume, 126,2018,Pages 729-755,ISSN 0360 8352, https://doi.org/10.1016/j.cie.2018.09.050

[14] Santos, R., Abreu, A., Matias, J.C.O.,Energy Efficiency in buildings by using evolutionary algorithms: An approach to provide efficiency choices to the consumer, considering the rebound effect, IFIP International Federation for Information Processing 2018, 2018-03-29, book-chapter Part of ISBN: 9783-319-78574-5

[15] Pombo, O., Allacker, K., Rivela, B., Neila, J., (2016) Sustainability assessment of energy saving measures: a multi-criteria approach for residential buildings retrofittingda case study of the Spanish housing stock, Energy Build. 116 pp.384e394.

[16] Aghay Kaboli , S. Hr., Selvaraj, J., Rahim, N.A.,(2017) Rain-fall optimization algorithm: A population based algorithm for solving constrained optimization problems, Journal of Computational Science, Volume 19, Pages 31-42, ISSN 1877-7503, https://doi.org/10.1016/j.jocs.2016.12.010

[17] Cortés, P., Muñuzuri, J., Berrocal-de-O, M., Domínguez, I., (2018) Genetic algorithms to optimize the operating costs of electricity and heating networks in buildings considering distributed energy generation and storage, Computers \& Operations Research, Volume 96, Pages 157-172, ISSN 03050548, https://doi.org/10.1016/j.cor.2018.01.020.

[18] K. Deb, A. Pratap, S. Agarwal and T. Meyarivan, "A fast and elitist multiobjective genetic algorithm: NSGA-II," in IEEE Transactions on Evolutionary Computation, vol. 6, no. 2, pp. 182-197, April 2002. doi: $10.1109 / 4235.996017$

[19] Chuah, J. W., Raghunathan, A., Jha, N. K. (2013), ROBESim: A retrofitoriented building energy simulator based on EnergyPlus, Energy Build., vol. 66, pp. 88-103.

[20] Asadi, E., Silva, M. G., Antunes, C. H., Dias, L. (2012), Multi-objective optimization for building retrofit strategies: A model and an application, Energy Build., vol. 44, pp. 81-87

[21] Mauro, G.M., Hamdy, M., Vanoli, G.P., Bianco, N., Hensen, J.L.M. (2015) A new methodology for investigating the cost-optimality of energy retrofitting a building category, Energy Build. 107 pp. 456 e 478 . 